\title{
Examining the Effectiveness of a Protected Areas Network in the Conservation of Kigelia africana under Climate Change by 2050 in Benin
}

\author{
Meminvegni Landry Gildas Guidigan ${ }^{*}$, Fortuné Azihou², Appollonia Aimiosino Okhimamhe1, \\ Brice Sinsin'2, Brahim Saratu Usman', Lucette Adet ${ }^{1}$
}

${ }^{1}$ WASCAL CC\&ALU Master Research Programme, FUT, PMB 65, Minna, Nigeria

${ }^{2}$ Laboratory of Applied Ecology, Faculty of Agronomic Sciences, University of Abomey-Calavi, Cotonou, Benin

Email: ^glguidigan@gmail..com, guidigan.m@edu.wascal.org

How to cite this paper: Guidigan, M.L.G., Azihou, F., Okhimamhe, A.A., Sinsin, B., Usman, B.S. and Adet, L. (2018) Examining the Effectiveness of a Protected Areas Network in the Conservation of Kigelia africana under Climate Change by 2050 in Benin. Open Access Library Journal, 5: e4326.

https://doi.org/10.4236/oalib.1104326

Received: January 11, 2018

Accepted: February 24, 2018

Published: February 27, 2018

Copyright $\odot 2018$ by authors and Open Access Library Inc.

This work is licensed under the Creative Commons Attribution International License (CC BY 4.0).

http://creativecommons.org/licenses/by/4.0/

\begin{abstract}
Sustainability of Kigelia africana species passes throughout their conservation. Protected area is recognised as the granary of species populations. Kigelia africana is an indigenous species and traditionally contributes to the resilience in term of health insurance, source of income, reduction of poverty and stability of the biodiversity. This study determines to find out 1) how Kigelia africana species populations' distributions may be affected under future climate scenarios, and 2) how well protected areas contribute to the conservation of Kigelia africana plant species. Available bioclimatic and soil data layers were used for the modelling with maximum entropy approaches, and resulting maps were overlaid on the existing protected areas network. Results showed that species distribution remains mainly much stable and the relationships with protected areas networks suggest that protected portions of species distributions will also remain stable.
\end{abstract}

\section{Subject Areas}

Agricultural Science, Biodiversity, Ecology, Ecosystem Science,

Environmental Sciences, Plant Science

\section{Keywords}

Biodiversity, Ecological Niche, Maximum Entropy, GIS, Representative Concentration Pathways

\section{Introduction}

Large percentage of Africa's protected areas was formed in response to declining 
large animal numbers [1]. Only recently have there been considered areas for the protection of biodiversity generally, of nature, or natural resources [2]. Species population has long been overlooked in the design to protected area systems. Plants species are the components of habitats and providing a refuge and the incubating sites for animals as well as contributing to climate change mitigation. Creating and managing protected areas is still critical to ensure the persistence of species [3]. As conservation continues to develop a "biodiversity for livelihoods" mandate, information on the ways, in which the protected areas network will respond to future climates especially for species population, is crucial. It seems then necessary to incorporate species' range shifts in spatial conservation plans to ensure their effectiveness in the future [1]. Furthermore, in Africa sub-Saharan zone, investigations on the potential climate change impact on the effectiveness of protected area networks in the conservation of indigenous species remained very rare. However, climate change is a fundamental factor which has ecological stress and challenged the effectiveness of protected areas networks in species conservation [4]. In sum, there are some strong doubts on how these static areas will still conserve species population or to provide theme as far as the climate change, the favourable habitats.

Among the African medicinal plants, Kigelia africana (Lam.) Benth. (syn. K. pinnata (Jacq.) DC.) for long time has been one of the most recognized species due to its pantropical distribution [5]. K. Africana is typically of the African continent where it is commonly found in the southern, central and western regions and widely used for multi-purpose by rural people for treatment of a wide range of diseases and also as an agroforestry tree. The plant has been introduced to some countries of South-East Asia like India, Pakistan, China, Philippines and Iraq where it is mainly cultivated as an ornamental tree, commonly found in gardens and parks, both for its beautiful deep red flowers and its strange fruits; also in Miami, Florida [6], where it grown as a flamboyant tree and provides shade from the scorching sun for the inhabitants.

Ecological niche modelling is a powerful tool to map the current distribution of a species and forecast its future variation. This tool has been used to investigate the impact of climate change on species distribution [7] and identify suitable areas where conservation actions are urgently needed to avoid extinction Modelling species distribution has been conducted using a diverse list of statistical methods to analyse environmental and presence/absence data to estimate the probability of occurrence of a given species at given geographic coordinates [8] Among these modelling tools, MaxEnt (maximum entropy modelling) is one of the most powerful tools as it provides highly informative biogeographical information and a better discrimination of suitable versus unsuitable areas for a species, compared to other methods [9].

\section{Material and Methods}

\subsection{Study Area}

This study was conducted in Republic of Benin, located between the parallels 
$6^{\circ} 30^{\prime}$ and $12^{\circ} 30^{\prime}$ of latitude North and the meridians $1^{\circ}$ and $3^{\circ} 40^{\prime}$ of longitude East with an area of $114,763 \mathrm{~km}^{2}$. Three major ecological regions characterize the study system. The climate is representative of the sub equatorial climate in the Guineo-Congolian region $\left(6^{\circ} 25^{\prime} \mathrm{N}-7^{\circ} 30^{\prime} \mathrm{N}\right)$ and dryer in the Sudano-Guinean $\left(7^{\circ} 30^{\prime} \mathrm{N}-9^{\circ} 30^{\prime} \mathrm{N}\right)$ and the Sudanian regions $\left(9^{\circ} 30^{\prime} \mathrm{N}-12^{\circ} \mathrm{N}\right)$ (Figure 1$)$.

\subsection{Species Occurrence Records and Environmental Data}

Exploratory survey throughout the country was conducted where 466 geo-referenced location data from Kigelia africana were recorded. From these, forest and protected areas records were extracted. Species present climate was describe using the nineteen (19) climate variables bioclim at a resolution of 2.50', derived from the global climate layers of the WorldClim database [10], added detailed soil layers analysed in the form of the Harmonized World Soil Database

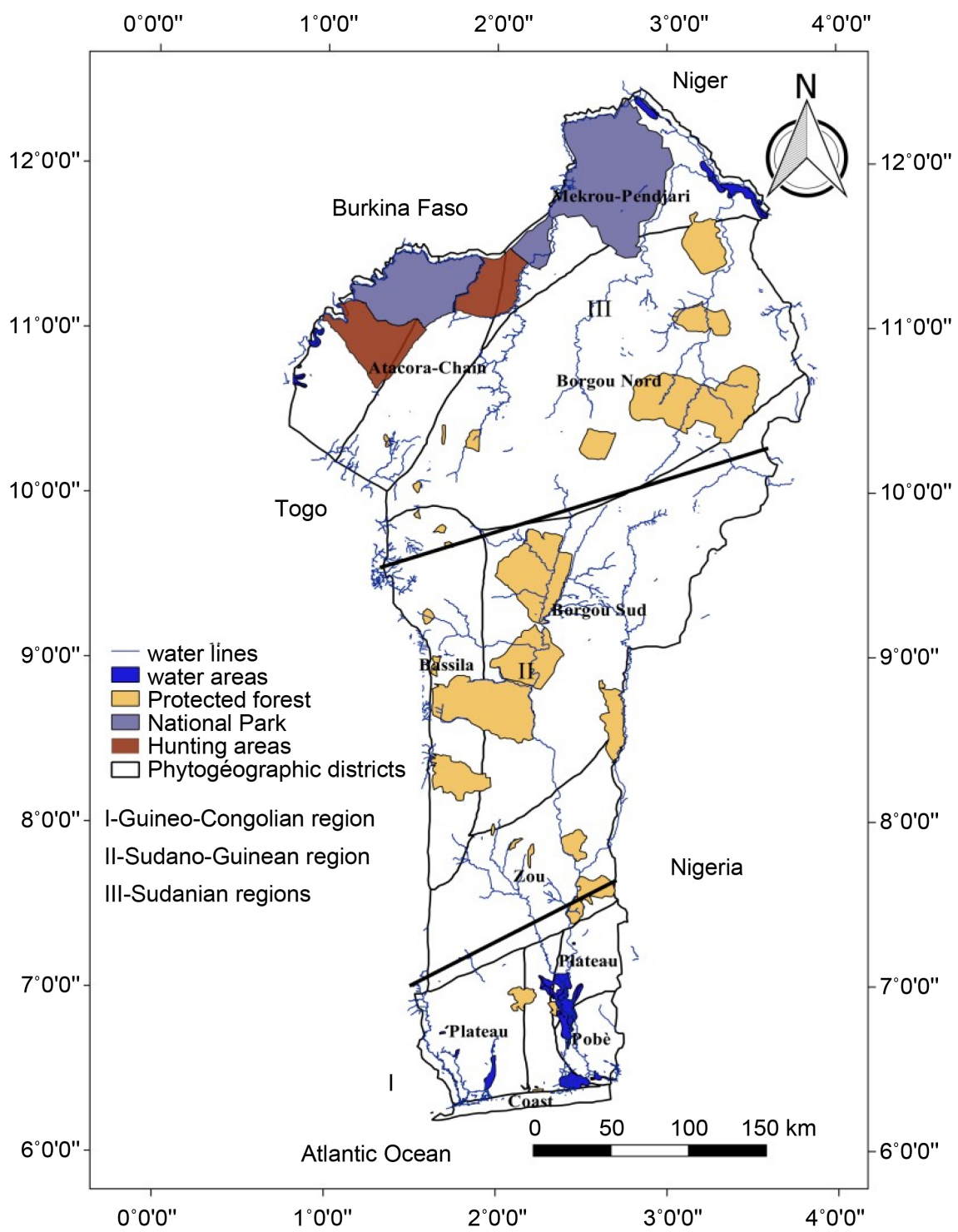

Figure 1. Map of Benin showing the ecological regions and the waterbody and water line. 
version 1.2 (FAO/IIASA/ISRIC/ISSCAS/JRC 2012) [11]. On account of common collinearity and non-independence of climate dimensions [12], correlated patterns among variable were examined to select those not closely correlated. In addition, Pearson correlation coefficients below 0.80 were included [13].

To analyze potential "future" climate projections on Kigelia africana, ensemble forecasting approach were used namely, HadGEM2-ES and CNRM-CM5, lately used for West Africa [14] [15]. These climate models comparatively with severe aspect of futurity status are based on the Representative Concentration Pathway (RCP) 8.5 for the 2050 time skyline. RCPs are the third generation of storyline and are preferred to Special Report on Emissions Scenarios (SRES) for sake they permit more flexibility (and reduced costs) in modelling procedure [16]. Scenario has been formed to investigate different combinations of demographic, socioeconomic, land use, and technology scenario backgrounds [17]. RCP 8.5 has already been used for studying African ecosystems [15] and represents an updated version of the SRES A2 scenario.

\subsection{Modelling the Distribution of the Species}

The area under curve (AUC) quantifies the significance of this curve that has values ranging between 0.5 and 1.0 [18] [19]. Area under the Receiver operating characteristic (ROC) Curve, recognized as the AUC, is generally used to evaluate the predictive correctness of dispersion models. Partial AUC were calculated using $\mathrm{R}$ software version 3.4.1. Bootstrapping management that allow the assessment of statistical significance of AUCs (as compared with null expectations) were accomplished by re-sampling $50 \%$ of the test point with substitute 1000 time from the overall pool of testing data. The important explanation of a given species distribution of each variable is determine by a Jackknife test [9].

MaxEnt [9] was used to evaluate relationship between the climate and the vegetation variables and occurrence of Kigelia africana species population. Although, MaxEnt is designed for use with presence-only data, it qualitatively resembles techniques such as logistic regression in that it compares presence locations to a random subset of $\sim 10,000$ background or available locations [9]. MaxEnt estimates probability distributions that are close to maximum entropy or uniform given constraints derived from the presence data and functions of the environmental variables [9]. Model output can be interpreted as the probability of presence under a similar level of sampling effort as was required to obtain the known presence data [20]. For Kigelia africana species population, five (5) random partitions of the occurrence localities were made. Each partition was created by randomly selecting $75 \%$ of the occurrence localities as training data, with the remaining $25 \%$ reserved for testing the resulting models [8]. We corrected for geographic sampling bias using background data, as using background data gave a substantial improvement in model performance [21] [22]. Thus, background data (also known as "pseudo-absences") that has similar geographical sampling bias as presence data [3]. 
Maps were threshold to binary to avoid effects of over fitting [23]. Highest threshold which included $95 \%$ of the input data used in model calibration was looked for. This approach was just the best way to prioritize correct prediction of presences and take into account the turbulent nature of biodiversity data [24]. The present-day map of Kigelia africana species was combined with the two future climate forecasts to generate a map showing agreement as regards the species distributional area and stability.

Output of MaxEnt were processed in Arcgis 10.1 using "Spatial analyst" tool of Argis 10.1 was used to estimated the area of each suitability habitat type [25]. The logistic probability value has been considered as indicator of quality of habitats favourable of the species population. It is generated by MaxEnt. The habitat considered as poorly suitable for Kigelia africana is the one that the occurrence probability inferior to "maximum training sensitivity and specificity threshold". If it between this value and the " 10 percentile logistic threshold" the habitat is said to be medium suitable areas and highly suitable areas for cultivation and conservation of Kigelia africana, if the probability is above the last value [26].

\section{Result}

Assessment of relationships between Kigelia africana species distributions and the protected areas network across Benin revealed some diversity, although protection levels will remain generally stable. The results from correlations analysis and Jackknife test permitted to identify six (06) less correlated variables $(r<$ 0.80 ) considered for the modelling. The average training AUC was 0.904 and the standard deviation was 0.013 and a projection significantly different from the random projection ( $\mathrm{p}<0.0001$; one-sided binomial test), this confirm the goodness of the model.However, temperature annual range (21.5\%), precipitation seasonality (coefficient of variation) (19.4\%), soil (15.6\%), temperature seasonality (standard deviation) (13.1\%), maximum temperature of warmest month $(11.8 \%)$ are variables have mostly contributed to the model.

Evaluation of relationship between Kigelia africana population distribution and the protected areas networks across Benin Republic showed a few diversities, even though protection areas levels will generally be stable (Figure 2 band 1 to 3) and (Figure 3). In the Guineo-Congolian zone, model showed some tendency toward expansion of the species population in Lama and Djigbe protected areas; future class expansion likely to be observed in presence area along the same protected areas. In Sudano-Guinean zone, some trend toward retraction of the $K$. africana population were showed by the model limited to presence areas and high expansion wide areas along the Kétou and Dogbo protected areas in Zouphytogeographical district, protected areas of Toui-Kilibo, in the Borgou South phytogeographical district, Wari-Maro, Monts Kouffephytogeographical district and Ouéme superior. According to the CNRM-CM5 model under the scenario RCP $8.580 \%$ of this area will remain very favourable to the species conservation by 2050 , with $1 \%$ loss of the very favourable habitat (Table 1 ) and 
Table 1. Dynamic of suitable areas for the culture and conservation of Kigelia africana.

\begin{tabular}{|c|c|c|c|c|c|c|c|}
\hline \multirow{2}{*}{ Models } & \multirow{2}{*}{ Scenarios } & \multicolumn{2}{|c|}{ High suitable area } & \multicolumn{2}{|c|}{$\begin{array}{c}\text { Medium } \\
\text { suitable area }\end{array}$} & \multicolumn{2}{|c|}{ Low suitable area } \\
\hline & & $\begin{array}{c}\text { Area } \\
\left(\mathrm{km}^{2}\right)\end{array}$ & $\begin{array}{c}\text { Trend } \\
(\%)\end{array}$ & $\begin{array}{c}\text { Area } \\
\left(\mathrm{km}^{2}\right)\end{array}$ & $\begin{array}{c}\text { Trend } \\
(\%)\end{array}$ & $\begin{array}{c}\text { Area } \\
\left(\mathrm{km}^{2}\right)\end{array}$ & $\begin{array}{c}\text { Trend } \\
(\%)\end{array}$ \\
\hline Present & & $21,803.25$ & & 4609.17 & & 587.57 & \\
\hline CNRM-CM5 & RCP8.5 & $21,795.62$ & +0.03 & 4655.99 & -1.02 & 548.38 & +6.67 \\
\hline HadGEM2-ES & RCP8.5 & $21,385.96$ & +1.91 & 5033.27 & -9.20 & 580.76 & +1.16 \\
\hline
\end{tabular}

Finally(-) i(-) indicates a loss of suitable areas and (+) a gain in habitat suitability.

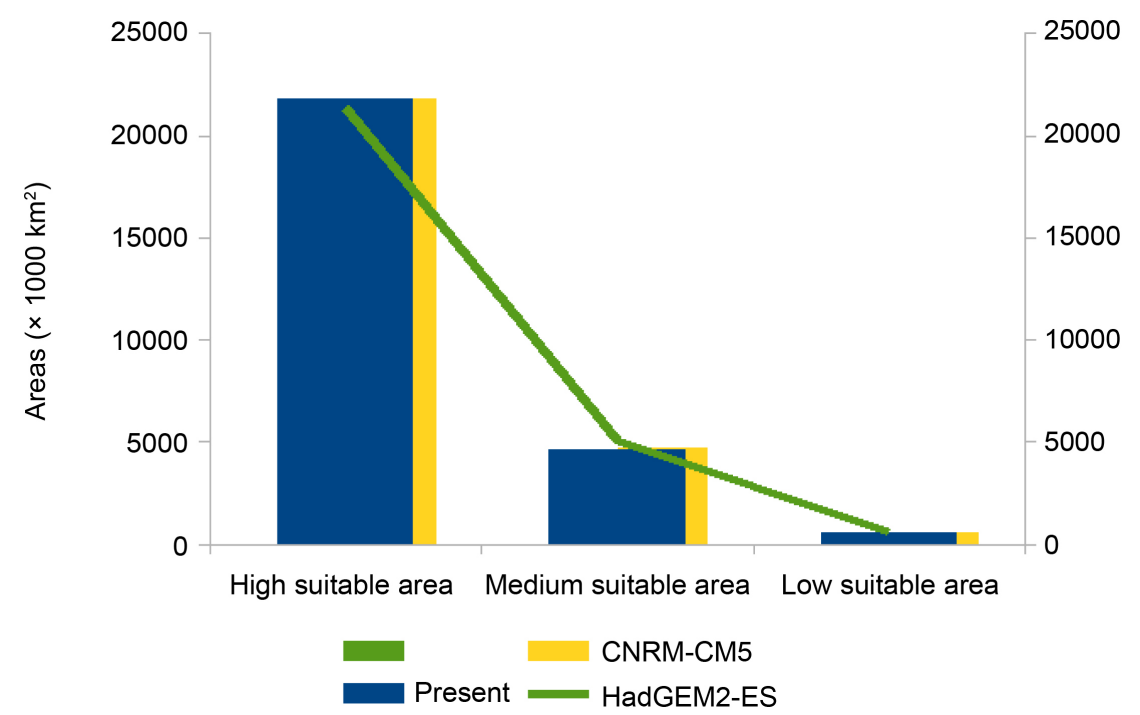

Figure 2. Variation in suitable areas to the cultivation and conservation of Kigelia africanaby 2050, according to the scenarios RCP 8.5 used in the two models CNRM-CM5 \& HadGEM2-ES.

(Figure 4). The HadGEM2-ES model under RCP 8.5 predicted 9\% loss this moderate favourable habitat to Kigelia africana conservation. It also predicted conversion of $2 \%$ of low favourable suitable area to a very favourable habitat by 2050 below $10^{\circ}$ the north in the protected area located in the Borgou. However, it also envisaged very favourable habitat conversion in Pendjari and Mékrou (between $10^{\circ} \mathrm{N}$ and $12^{\circ} 2^{\prime} \mathrm{N}$ of the Benin Republic) (Table 1) and (Figure 5).

\section{Discussion}

Impact of climate change of the favourable habitats of $K$. africana in protected areas by 2050. Protected areas are the only reserves which still are favourable to the conservation of the biodiversity [27]. Our solution advised that the current protected areas networks is very favourable to the conservation of Kigelia africana population. CNRM-CM5 and HadGEM2-ES model predicted a decrease in moderate favourable habitats to the species within Benin's networks of protected areas while both model at the same time predicted their extension. The Figures 6-8 showed respectively the curves respond to the annual range of temperature, 


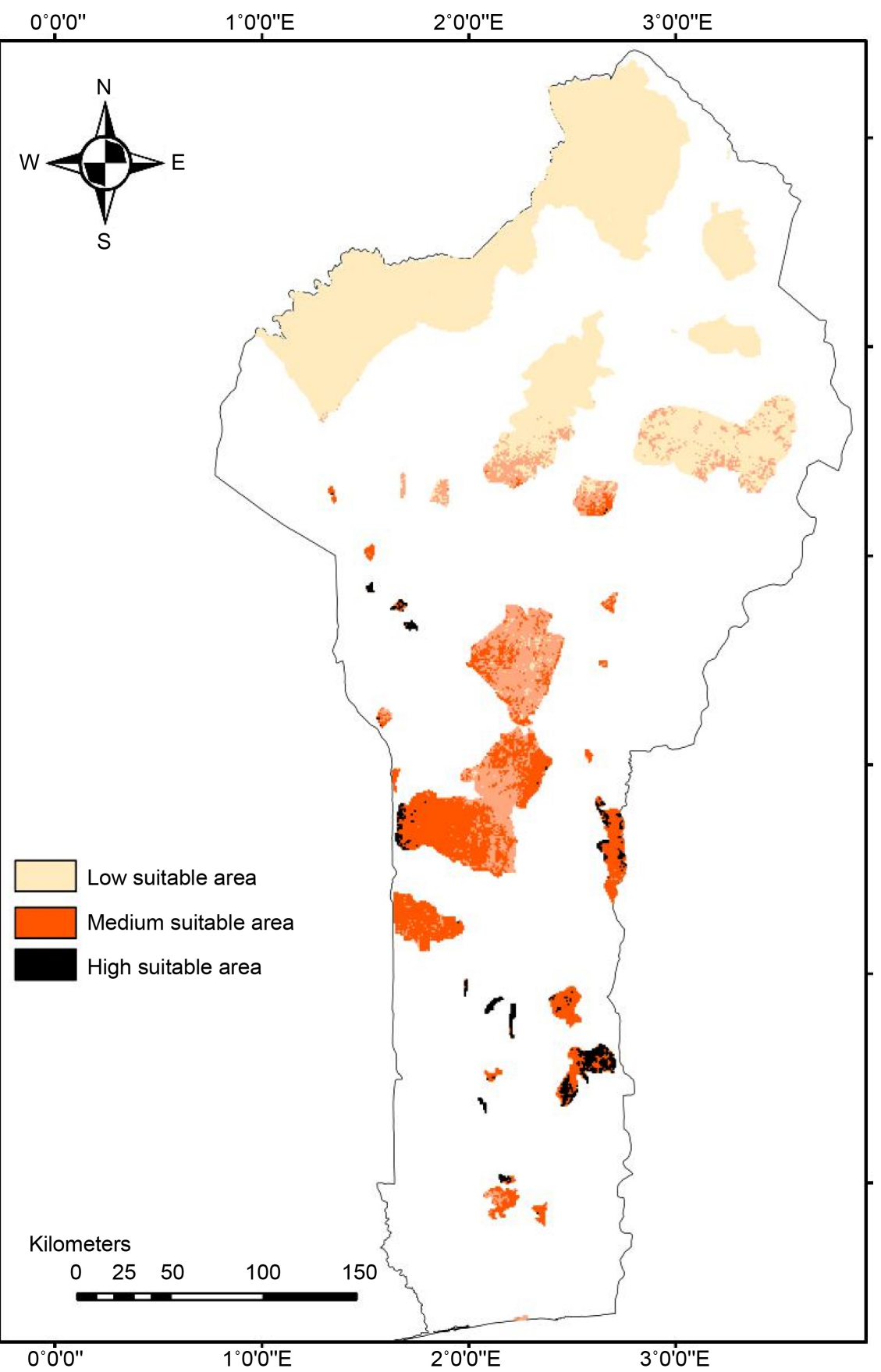

Figure 3. Current suitable habitat of Kigelia africana conservation in protected area.

the precipitation seasonality and temperature seasonality. The Figure 9 showed the AUC value. Evaluation of the relationship of Kigelia africana species distributed field present full demonstrated good possibility of present protected areas to preserve species population. Moreover, our future model projections forecast constancy in protected areas species distributions connection, despite the fact that expansion and reduction may happen just about cases. These results corroborate the hypothesis that protected areas in effect conserve Kigelia africana current and in the future. Most species distribution remains mostly static to face 


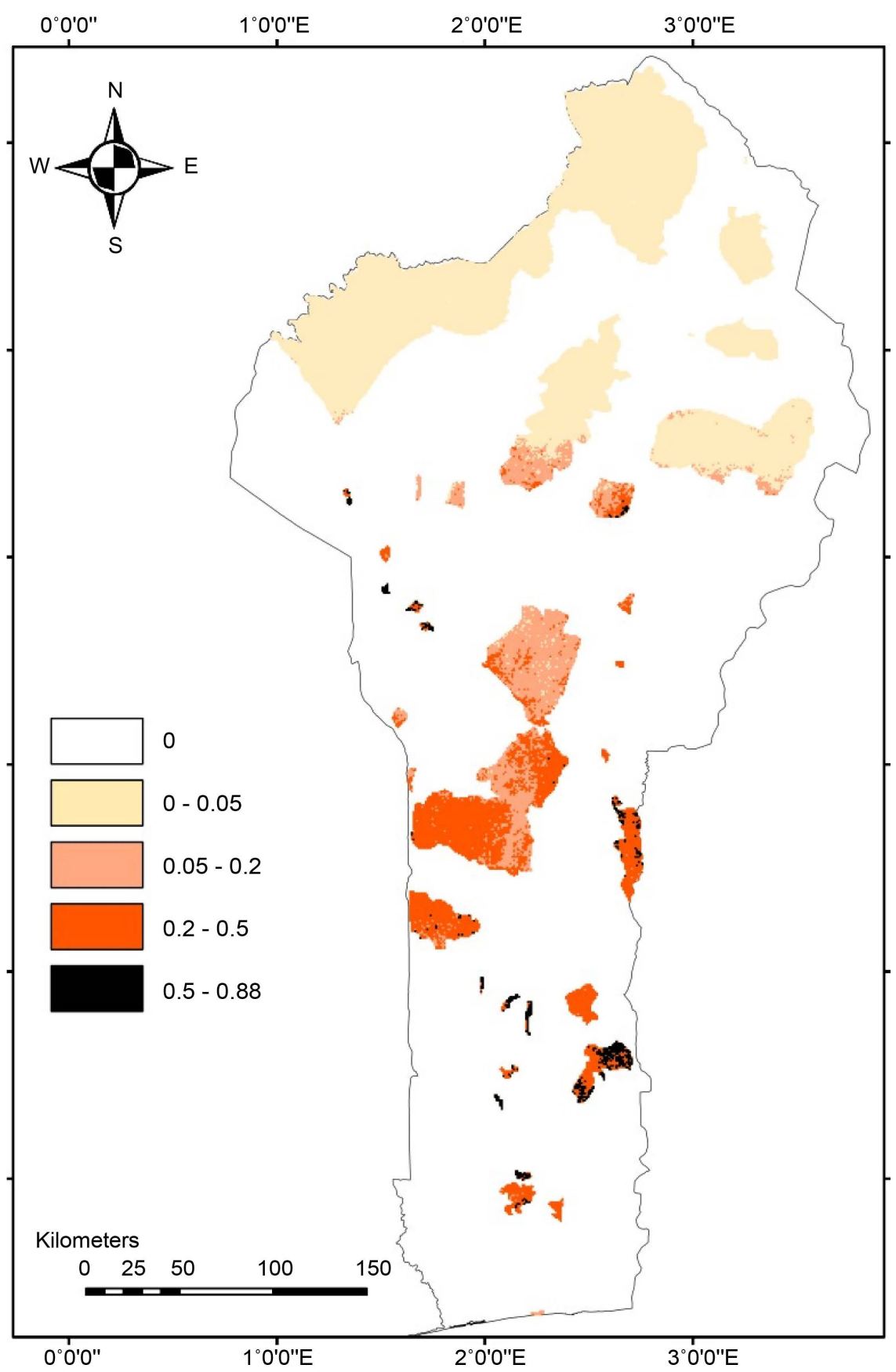

Figure 4. Future (2050) suitable habitat of Kigelia africana conservation as predicted by CNRM-CM5 climatic model.

a future climate change, even under the most forceful storyline. However, anthropogenic factor on species continues and habitats, sometimes causing unpredictable change to landscapes that can lead to vanish of species and conversion of current protected areas to Agroforestry scheme.

One of the principal activities pursued by the researchers in biodiversity and biological conservation is designation and execution of preventive measures that help to reduce the risk of extinction. Ecological niche modelling can be seen as a 


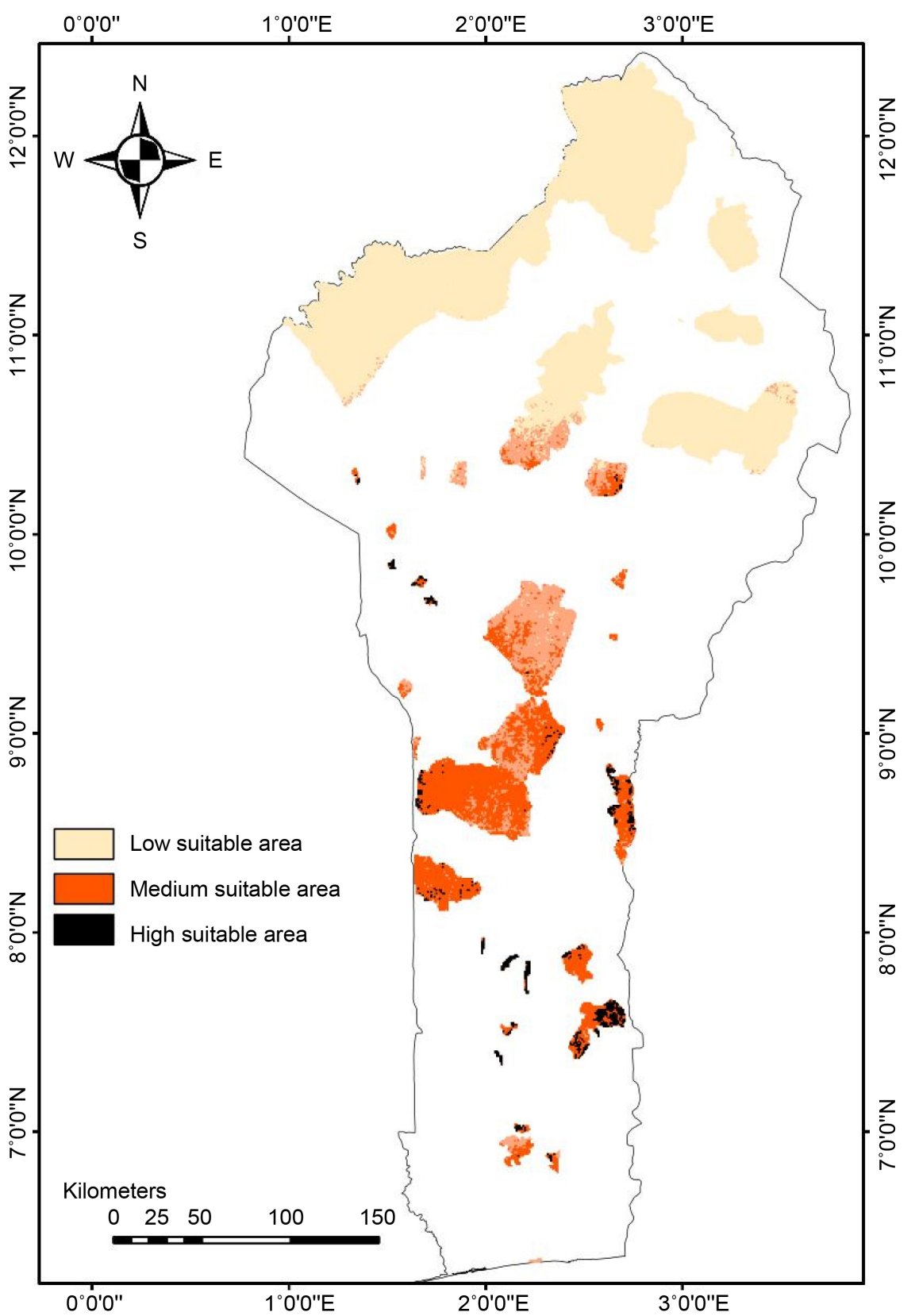

Figure 5. Future (2050) suitable habitat of Kigelia africana conservation as predicted by HadGEM2-ES climatic mode.

powerful tool for achieving this goal. But this tool has some weaknesses. In spite of these weaknesses, it provides important bioclimatic information in decision-making [28]. The current favourable condition for cultivation and conservation of Kigelia africana relate to the environment variables as annual temperature, seasonality precipitation and soil with its physico-chemical characteristics, temperature seasonality, max temperature of warmest month. Bioclimatic variation conditions over time can make these areas which are currently very favourable to the area that are relatively favourable to the conservation and cultivation of Kigelia africana and in some cases area that are currently very 
Response of Kigelia_africana to bio7

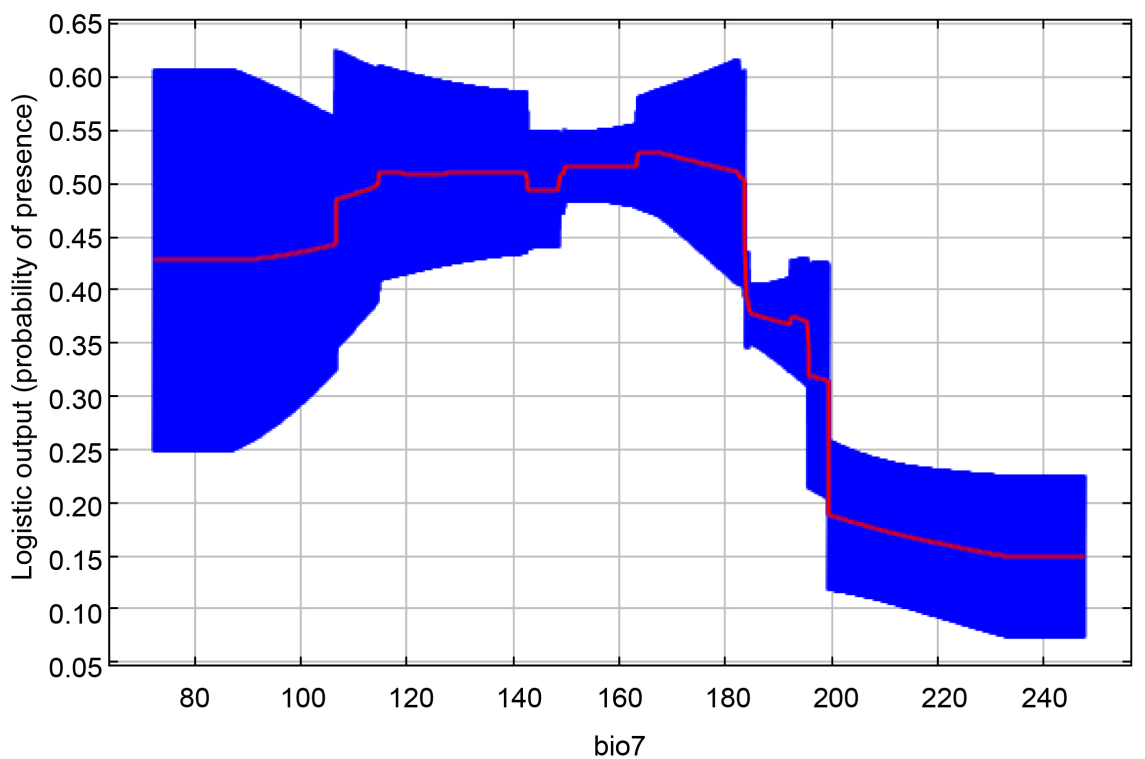

Figure 6. Curves showing the response of Kigelia africana to the temperature annual range.

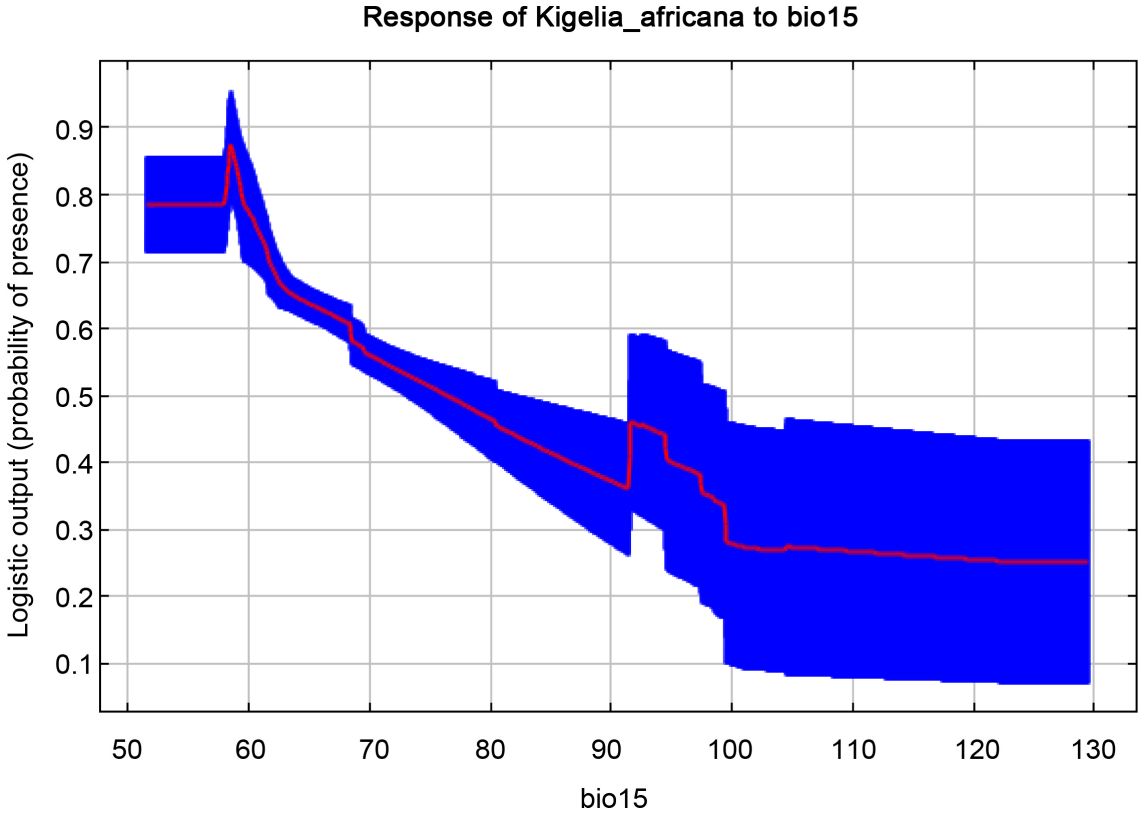

Figure 7. Curves showing the response of $K$. africana to the precipitation seasonality.

favourable to the areas that are not favourable to the conservation of Kigelia africana. Indeed, fluctuations in climate variables such as precipitation and temperature will affect biodiversity and geographic distribution of the species-friendly habitats [29]. Thus, it should be noted that anthropogenic actions influencing greatly climate factors and soil condition by increasing greenhouse gases (GHG) and radiative forcing rates which determine the species distribution habitats.

Although having a degradation experiences over the time, the protected 


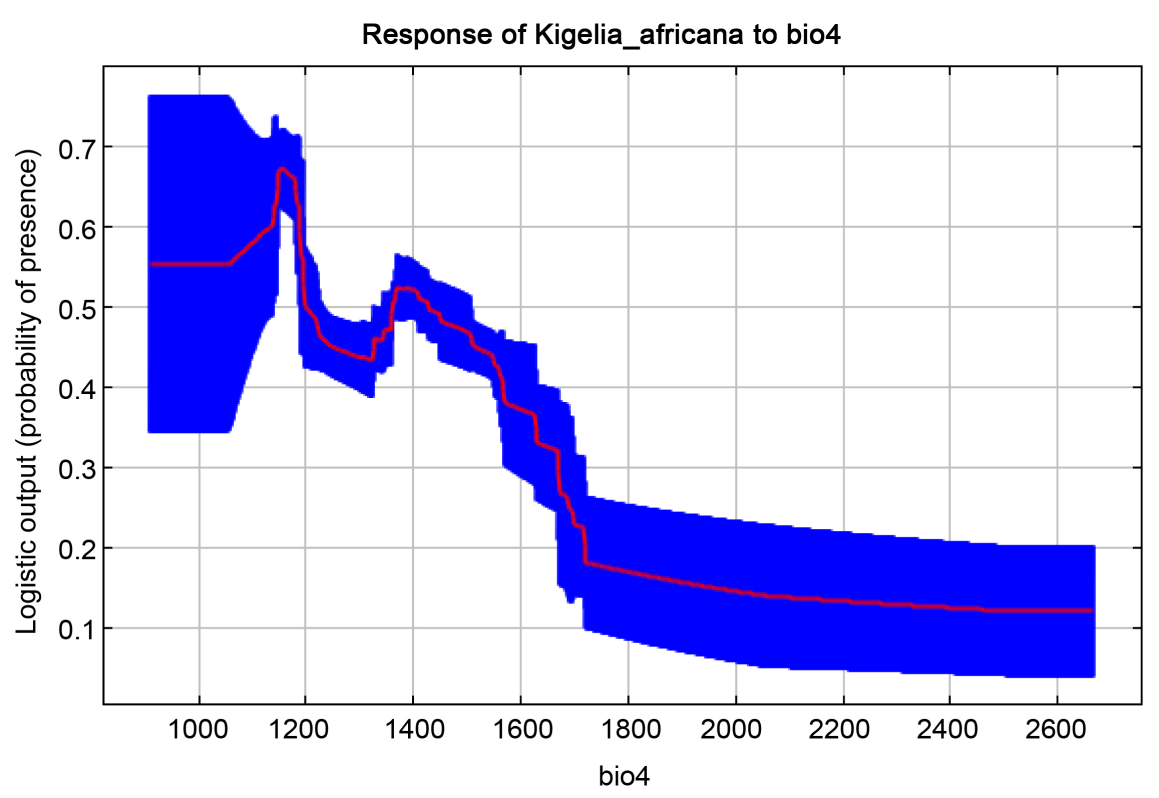

Figure 8. Curves showing the response of $K$. africana to temperature seasonality.

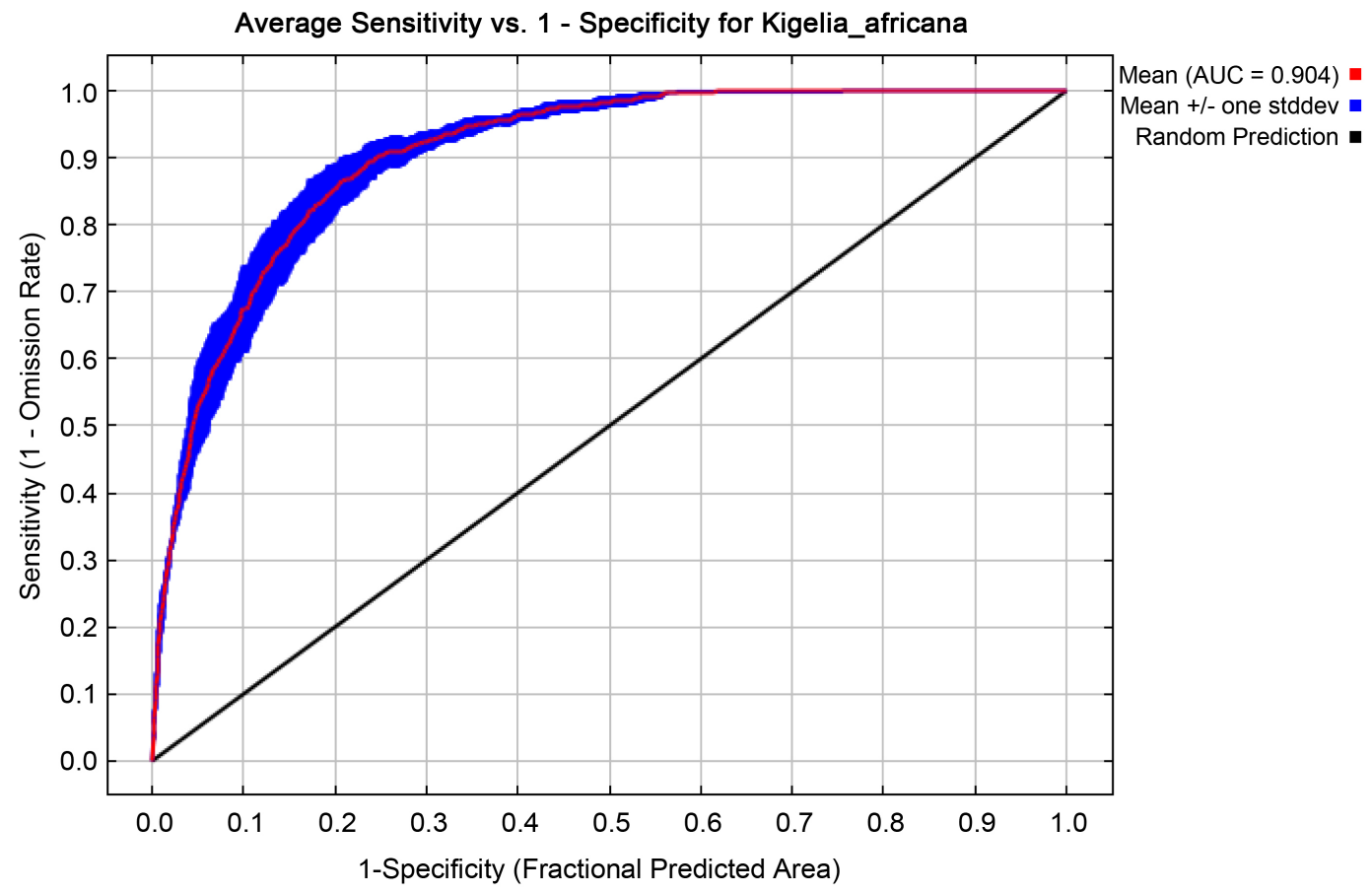

Figure 9. Show the fractional predictive area.

networks areas of Benin present a favourable areas to the conservation of the Kigelia africana species but at smaller proportion. This is the case of Pendjari Biosphere Reserve, the $\mathrm{W}$ park and the Lama forest. The climatic conditions prevailing in the current Sudanian zone (semi-arid and dry sub-humid zones) are very favourable to the conservation of Kigelia africana. Considering the increase of precipitation (CNRM-CM5 models), the zones currently very favourable to their conservation (semi-arid and dry sub-humid) could remain very fa- 
vourable by 2050. In case of decreases in precipitation (model HadGEM2), in the Guineo-Congolian and Sudano-Guinean region the areas that are currently very favourable (sub-humid humid zone) may become less favourable. In the dryness scheme (HadGEM2-ES), the culture and preservation of the species population would be likely throughout the protected areas. Similarly, the national protected networks areas offers very favourable conditions for the conservation of the species population. Despite projected reduction, whatever the projection, this network remains providing habitats that are highly favourable to the local species by 2050 . Thus, it will be more appropriate to develop a new model able to predict the dynamics of landscapes of protected areas and the species with great socio-economic importance, taking into account the effects of climate change and land use change. It will be necessary to revise the management of existing protected areas if we need that their role of conservation of biodiversity and support adaptation to climates change based on complete result, doing projection scenario emissions over reasonable horizons because, future farness can bias decision making and move away from the reality and the field work data. Moreover, the establishment of up-to-date databases on the potential impact of climate change species in relation to the different scenarios usable could support researchers and conservation decision-making in conservation context. Among the protected areas networks in Benin, the Pendjari Biosphere Reserve, the hunting areas of Park W (Djona and Mékrou), the classified forest of Goungoun and the classified forest of the Lama will better guarantee the conservation of Kigelia africana by 2050. To this end, it would be important to create in the southern part of the country other Protected Areas that will certainly remain more humid by 2050 in order to guarantee the conservation of the species in these environments. Likewise, it is very important to the decision maker to increase the protected areas which remains the guarantee of the species. In addition, weather effects adverse on protected areas will be combined with other forms of stress, including anthropogenic affect such as over-consumption (bark of Kigelia africana), pollution of urbanization. Biodiversity in protected areas, which may already be threatened by human activity, risks a more rapid and sever impoverishment due to climate change.

\section{Conclusion}

The parameters sum of maximum temperature of the warmest month and minimum temperature of the coldest month (bio7), precipitation seasonality (bio15), soil abiotic variable, temperature seasonality (bio4), maximum temperature of the warmest month (bio5) are the most contributors to the model. The most suitable and favourable area is found in the Guineo-Congolian and Soudano-Guinean region.

\section{Acknowledgements}

The present study was supported by the West Africa Science Service Center on 
Climate Change and Adapted Land Use (WASCAL). The authors are grateful to Prof. ADOMOU Director of the National Herbarium of Benin, Dr. Rodrigue IDOHOU of Laboratory of Biomathematics and Forest Estimations (LABEF), University of Abomey-Calavi, for advice and guidance on using the MaxEnt algorithm.

\section{References}

[1] Balmford, A. and Albon, S.B.S. (1992) Correlates of Male Mating Success and Female Choice in a Lek-Breeding Antelope. Behavioral Ecology, No. 3, 112-123. https://doi.org/10.1093/beheco/3.2.112

[2] Marshall, A., Platts, P.J., Gereau, R.E., Kindeketa, W., Kang'ethe, S. and Marchant, R. (2012) The Genus Acacia (Fabaceae) in East Africa: Distribution, Biodiversity and the Protected Area Network. Plant Ecology Evlu, 145, 289-301.

https://doi.org/10.5091/plecevo.2012.597

[3] Idohou, R., Assogbadjo, A.E., Kakaï, R.G. and Peterson, A.T. (2016) Spatio-Temporal Dynamic of Suitable Areas for Species Conservation in West Africa: Eight Economically Important Wild Palms under Present and Future Climates. Agroforestry Systems, 91, 527-540. https://doi.org/10.1007/s10457-016-9955-6

[4] Fandohan, B., Gouwakinnou, G.N., Fonton, N.H., Sinsin, B. and Liu, J. (2013) Impact of Climate Change on the Geographical Distrubution of Suitable Areas for Cultivation and Conservation of Underutilized Fruit Trees: Case Study of the Tamarind Tree in Benin. Biotechnologie, Agronomie, SociétéetEnvironnement, 17, 450-462. http://popups.ulg.ac.be/Base/document.php?id=10186\&format=print

[5] Sofowora, A. (1980) The Present Status of Knowledge of the Plants Used in Traditional Medicine in Western Africa: A Medical Approach and a Chemical Evaluation. Journal of Ethnopharmacology, 2, 109-118. https://doi.org/10.1016/0378-8741(80)90004-5

[6] Kaur, H., Shyam, R. and Amutha, R. (2011) Kigelia africana Fruit Carbon as a Low Cost Adsorbent for Removal of Copper (II) Ions from Aqueous Solution. Nature Environment and Pollution Technology, 10, 419-422.

[7] van Zonneveld, M., Koskela, J., Vinceti, B. and Jarvis, A. (2009). Impact of Climate Change on the Distribution of Tropical Pines in Southeast Asia. Unasylva, 60, 24-29.

[8] Guisan, A. and Zimmermann, N.E. (2000) Predictive Habitat Distribution Models in Ecology. Ecological Modelling, 135, 147-186. https://doi.org/10.1016/S0304-3800(00)00354-9

[9] Phillips, S.B., Aneja, V.P., Kang, D. and Arya, S.P. (2006) Modelling and Analysis of the Atmospheric Nitrogen Deposition in North Carolina. International Journal of Global Environmental Issues, 6, 231-252. https://doi.org/10.1504/IJGENVI.2006.010156

[10] Hijmans, R.J., Cameron, S.E., Parra, J.L., Jones, P.G. and Jarvis, A. (2005) Very High Resolution Interpolated Climate Surfaces for Global Land Areas. International Journal of Climatology, 25, 1965-1978. https://doi.org/10.1002/joc.1276

[11] Sanchez, A.C., Osborne, P.E. and Haq, N. (2010) Identifying the Global Potential for Baobab Tree Cultivation using Ecological Niche Modelling. Agroforestry Systems, 80, 191-201. https://doi.org/10.1007/s10457-010-9282-2

[12] Zuur, A.F., Ieno, E.N. and Elphick, C.S. (2010) A Protocol for Data Exploration to Avoid Common Statistical Problems. Methods in Ecology and Evolution, 1, 3-14. 
https://doi.org/10.1111/j.2041-210X.2009.00001.x

[13] Elith, J., Kearney, M. and Phillips, S. (2010) The Art of Modelling Range-Shifting Species. Methods in Ecology and Evolution, 1, 330-342.

https://doi.org/10.1111/j.2041-210X.2010.00036.x

[14] Good, P., Jones, C., Lowe, J., Betts, R. and Gedney, N. (2013) Comparing Tropical Forest Projections from Two Generations of Hadley Centre Earth System Models, HadGEM2-ES and HadCM3LC. Journal of Climate, 26, 495-511. https://doi.org/10.1175/JCLI-D-11-00366.1

[15] Panitz, H., Schubert-frisius, M., Meier-fleischer, K., Lenzen, P., Keuler, K., Luethi, D., Dosio, A., et al. (2013) CORDEX Climate Simulations for Africa using COSMO-CLM (CCLM). Geophysical Research Abstracts, 15, EGU2013-1387.

[16] vanVuuren, D.P., Edmonds, J., Kainuma, M., Riahi, K., Thomson, A., Hibbard, K., Rose, S.K., et al. (2011) The Representative Concentration Pathways: An Overview. Climatic Change, 109, 5-31. https://doi.org/10.1007/s10584-011-0148-Z

[17] Moss, R.H., Edmonds, J.A., Hibbard, K.A., Manning, M.R., Rose, S.K., van Vuuren, D.P., Nakicenovic, N., et al. (2010) The Next Generation of Scenarios for Climate Change Research and Assessment. Nature, 463, 747-756.

https://doi.org/10.1038/nature08823

[18] Engler, R., Guisan, A. and Rechsteiner, L. (2004) An Improved Approach for Predicting the Distribution of Rare and Endangered Species from Occurrence and Pseudo-Absence Data. Journal of Applied Ecology, 41, 263-274. https://doi.org/10.1111/j.0021-8901.2004.00881.x

[19] Kumar, S. and Stohlgren, T.J. (2009) Maxent Modeling for Predicting Suitable Habitat for Threatened and Endangered Tree Canacomyricamonticola in New Caledonia. Journal of Ecology and Natural Science, 1, 94-98.

[20] Carroll, C. (2010) Role of Climatic Niche Models in Focal-Species-Based Conservation Planning: Assessing Potential Effects of Climate Change on Northern Spotted Owl in the Pacific Northwest, USA. Biological Conservation, 143, 1432-1437. https://doi.org/10.1016/j.biocon.2010.03.018

[21] Phillips, S.J., Dudík, M., Elith, J., Graham, C.H., Lehmann, A., Leathwick, J. and Ferrier, S. (2009) Sample Selection Bias and Presence-Only Distribution Models: Implications for Background and Pseudo-Absence Data. Ecological Applications, 19, 181-197. https://doi.org/10.1890/07-2153.1

[22] Syfert, M.M., Smith, M.J. and Coomes, D.A. (2013) The Effects of Sampling Bias and Model Complexity on the Predictive Performance of MaxEnt Species Distribution Models. PLOS ONE, 8, e55158.

https://doi.org/10.1371/annotation/35be5dff-7709-4029-8cfa-f1357e5001f5

[23] Peterson, A.T., Soberón, J., Pearson, R.G., Anderson, R.P., Martínez-Meyer, E., Nakamura, M. and Araújo, M.B. (2011) Ecological Niches and Geographic Distributions.

[24] Peterson, A.T. and Soberón, J. (2012) Species Distribution Modeling and Ecological Niche Modeling: Getting the Concepts Right. Natureza a Conservacao, 10, 102-107. https://doi.org/10.4322/natcon.2012.019

[25] Martínez, I., Carreño, F., Escudero, A. and Rubio, A. (2006) Are Threatened Lichen Species Well-Protected in Spain? Effectiveness of a Protected Areas Network. Biological Conservation, 133, 500-511. https://doi.org/10.1016/j.biocon.2006.08.003

[26] Liu, C., Berry, P.M., Dawson, T.P. and Pearson, R.G. (2005) Selecting Thresholds of Occurrence in the Prediction of Species Distributions. Ecography, 28, 385-393. https://doi.org/10.1111/j.0906-7590.2005.03957.x 
[27] Houinato, M., Sinsin, B. and Lejoly, J. (2001) Impact des feux de broussesur la dynamique des communautésvégétalesdans la forêt de Bassila (Bénin). Acta Botanica Gallica, 8078, 37-41.

[28] Ayihouenou, E.B. (2014) Modélisation de la répartitiongéographique des airesfavorables à la culture et à la conservation de Parkiabiglobosa sous influence des changementsclimatiques au Bénin. Thes. Doc, University of Abomey-Calavi, 89.

[29] IPCC (2007) Climate Change 2007: Impacts, Adaptation and Vulnerability: Contribution of Working Group II to the Fourth Assessment Report of the Intergovernmental Panel. Genebra, Suíça. 